Change levers for unifying top-down and bottom-up approaches to the adoption and diffusion of e-learning in higher education

Dr Gurmak Singh and Prof. Glenn Hardaker*

Affiliations

Dr Gurmak Singh, Faculty of Social Science, University of Wolverhampton, United Kingdom; Prof. Glenn Hardaker, Sultan Hassanal Bolkiah Institute of Education, Universiti of Brunei, Brunei Darussalam.

*Corresponding author. Sultan Hassanal Bolkiah Institute of Education, Universiti of Brunei, Brunei Darussalam, E-mail: glenn.hardaker@ubd.edu.bn 


\begin{abstract}
Using Giddens' theory of structuration as a theoretical framework, this paper outlines how five prominent United Kingdom universities aimed to integrate top-down and bottom-up approaches to the adoption and diffusion of e-learning. The aim of this paper is to examine the major challenges that arise from the convergence of bottom-up perspectives and top-down strategies. Giddens' theory is used to understand the dynamics of organisational change as they pertain to the adoption and diffusion of e-learning. This is intended to support our understanding of the interplay between top-down strategy and bottom-up adoption of elearning. From the research and from our findings, we present a set of change levers that are intended to provide practical value for managers responsible for the diffusion of e-learning strategy in higher education.
\end{abstract}

Keywords: diffusion of strategy; technology enhanced learning; adoption of e-learning 


\section{Change levers for unifying top-down and bottom-up approaches to the adoption and diffusion of e-learning in higher education}

\section{Introduction}

Most research into the adoption and diffusion of learning technologies can be split into topdown (macro-level) and bottom-up (micro-level) studies. Top-down studies have been concerned with radical and systemic development that transforms entire institutions through organisational and structural change. The main focus of studies in this category is to develop organisational theories in which technology is a major driver of change. Such studies have generally focused on the development of technologies, top-down e-learning strategies, the role of senior managers, and support and reward structures (Benson \& Palaskas, 2006; de Freitas \& Oliver, 2005; Schneckenberg, 2010). However, researchers focusing only on macro-level factors have been criticised for limiting opportunities to take account of the complex, ambiguous, and networked nature of technologies (Birch \& Burnett, 2009; Marshall, 2010; Oblinger, 2012; Salmon, 2005). Bottom-up approaches, conversely, focus on the various parts of an institution that may benefit from innovations. Typically, these approaches are less concerned with radical transformation of the entire educational system. The aim of research studies using this approach is to develop theories of technology adoption that will aid widespread application. Recently, there has been a significant surge in the number of studies that have focused on the views and perspectives of academic teaching staff (de Freitas \& Oliver, 2005; Lisewski, 2004). The focus of these studies is mainly on staff attitudes and motivations to using technology and they place prominence on organic and emergent change driven by innovators and early adopters of e-learning (Hardaker, Dockery, \& Sabki, 2010).

There is a wide-spread consensus that a number of factors influence the adoption of elearning, including the impact of technologies on teaching practices (Birch \& Burnett, 2009), personal motivations, attitudes towards technology (Osika, 2006), and psychological motivations within the institutional context. The adoption of e-learning influences institutional strategy (Stiles \& Yorke, 2006), role of senior managers (Benson \& Palaskas, 2006; Marshall, 2004), resources, and support (Nicol \& Draper, 2007). Many studies have highlighted difficulties with top-down e-learning strategies that are based on management directives related to technology implementation (Birch \& Burnett, 2009; de Freitas \& Oliver, 2005; Marshall, 2010). The thrust of the literature examining top-down and bottom-up 
approaches is that there needs to be increased support from top managers for e-learning projects that originate from an individual staff member or a small group, which requires flexible, open, and responsive structures and strategies (Backhouse, 2013). A few studies have attempted to reconcile top-down and bottom-up approaches in order to gain a shared commitment from academic staff and senior managers (Drlika \& Skalkaa, 2011; Marshall, 2010; Sharpe, Benfield, \& Francis, 2006).

The adoption of only a single approach to e-learning adoption, whether top-down or bottom-up, can lead to a number of limitations, because only part of the innovation is observed, and, therefore, the findings of analysis may not enable full acknowledgement of the innovation's complex effects (Lisewski, 2004; Marshall, 2004). Singh and Hardaker (2014) conducted an extensive review of the literature on the factors that influence the decision to adopt e-learning among academic teaching staff and on institutional structures that enable or hinder the diffusion of e-learning in higher education contexts. They concluded that there remains a need for further research that develops a more integrated theoretical framework to close the gap between top-down and bottom-up approaches. Such a framework may provide a means to investigate the influence of both exogenous factors and individual strategies.

The aim of this study is, using an integrated theoretical framework, to examine the major challenges that arise from the convergence of bottom-up and top-down strategies. By doing so, the researchers seek to meet the following two objectives:

1) identify and examine the inhibitors and enablers that influence the convergence of top-down and bottom-up approaches, and

2) propose a set of change management levers to structures that enable the effective development, adoption, and diffusion of e-learning.

\section{Theoretical framework}

Giddens (1984) developed the theory of structuration in an endeavour to reconcile the divide between those who perceive phenomena as shaped by structures and those who view phenomena as a result of human agency. He did not view structure and agency as independent or incompatible, but as mutually interacting elements of a duality. Structuralists and functionalists (macro-level theorists), Giddens argued, have provided explanations of social behaviour in terms of structural forces that limit the capability of individuals to act autonomously. On Giddens' theory, neither structure nor agency is primary; rather, social life as a micro-level activity can only be studied in relation to the macro-level context.

Structuration refers to the conditions governing the structures and is "perceived as a social 
process that requires interaction between human actors and institutional features" (Giddens, 1984, p. 25). Giddens does not explicitly address the issue of technology in his structuration paradigm (Jones \& Karsten, 2008). Nevertheless, structuration theory has been deployed to study technology-induced organisational change (Rose, 1998) and in the domain of information technology innovations (Bhowmick, 2015). Orlikowski and Robey (1991) adapted the structural theory for information technology. Their adaptation was based on the premise that technological systems are developed by actors within their social contexts, and that these technological systems are socially constructed by the different meanings given by the actors, who emphasise various features of the systems.

Giddens' duality of structure contends that human agency takes place through and because of structure. Individuals engage with these structures to give them shape and form. This interplay between human agency and structures offers considerable analytic advantages. The interaction between agents and structures within specific contexts is depicted in Giddens' stratification model. Modalities are dimensions of the interaction, which relate agents' knowledge and capacities to structural features (Rose \& Hackney, 2003). Modalities provide a way of conceiving of the connecting links between agents' knowledge and capacities, on the one hand, and the structural features of social system, on the other (Brooks, Atkinson \& Wainwright, 2008).

\section{Overview of the e-learning projects}

The primary criteria for selection of the case study institutions were eLearning innovation had been recently introduced. For each case project there needed to be scope for interaction between the individual adopters (agency) and the structure. The emphasis was upon the construction of meanings and perspectives, the adaptation to circumstances and flow of interactions. Thus, case organisations needed to provide access to individuals who had experienced the phenomenon. These respondents selected for the research needed to be involved in the development of eLearning teaching and learning material, responsible for providing technical or administrative support, or responsible for management of the eLearning project. For each case project there needed to be scope for interaction between the individual adopters (agency) and the structure, thus individual eLearning projects that involved no interaction with other institutional mechanisms were not selected.

The Case A is a post-1992 university in England. The University has an explicit commitment to eLearning written into its Learning and Teaching Strategy. At the time of this 
study, the Professor for eLearning had finalised the new TSL (Technology Supported Learning) strategy for the institution. One of the primary aims of the institution is to increase student numbers by broadening the pool of potential learners through more flexible provision. The drive towards distant learning programmes supported by instructional technologies is underpinned by a number of factors, such as: the fall in recruitment numbers on traditional courses in some subject areas, changes in student expectations in terms of the use of technology and flexible learning, the gap in the market for distance learning courses, existing institutional experience, local competition, government (visa) policies, improved quality of distance learning students, and flexible finance (fees).

The Professor for eLearning was charged with developing the strategy. The initial discussions took place between the Professor for eLearning, Deputy Vice Chancellor and the Finance Office. This was followed by discussion with Heads of Faculties and their Heads of Teaching and Learning. Further discussions took place with Team Heads and the Head of Information Services, Dean of Student Services, and the Dean of Students. The feedback from each of these groups was used to develop the eLearning strategy by the Professor of eLearning. A 'devolved' approach to eLearning was adopted by the institution where the eLearning strategy allowed for 'non-standard' approaches. The Professor for eLearning acknowledged that diverse practices within the institution exist in the adoption of instructional technologies. The need to reconcile the need for consistent and high quality eLearning courses and allow for individual innovation and preferences was one of the aims of the eLearning strategy.

Case B is a post-1992 multi-campus university in England. The Vice Chancellor tasked the Pro-Vice Chancellor for teaching and learning to set up a group to consider the institution's eLearning strategy. The group consisted of the Head of Information, Head of Blended Learning, Dean of Learning, Head of IT services, representative from the Student Union, and Dean of IT. The institution concluded that the existing VLE was unable to support eLearning student rights that were key components of the eLearning strategy and thus, an upgrade to the institutional VLE was sanctioned. Subsequently an upgrade version of the VLE was developed and this was to be rolled out to each school. The institutional IT development team were tasked with developing a new VLE that maintained the features and interface of the existing one, but additionally incorporated Web2 technologies. The features to be included were drawn up by a cross-university group mainly comprising staff from IT services and the Centre for Learning and Teaching, and not including any of the academic teaching staff. Head of Blended Learning Unit, a senior member of the institution, was 
responsible for implementing the institutional eLearning strategy. Technology Supported Learning co-coordinators, one for each faculty, were charged with managing the implementation of the new VLE at faculty level. Heads of Academic Departments were responsible for ensuring their staff complied with the eLearning requirements set by the University.

Institution $\mathrm{C}$ is one of the largest universities in the United Kingdom with more than 32,000 students. The institutional eLearning strategy recognised different needs of each faculty and allowed each department and faculty to develop their own eLearning strategy that included planning for coherent integration of blended and fully-online learning in all programmes. The e-learning strategy at University $\mathrm{C}$ reflected the fact that each faculty has different needs and allowed each department and faculty to develop its own strategy, which included planning for coherent integration of blended and fully-online learning in all courses. Technology such as animations, on-line formative assessment strategies and video clips were utilised to aid student understanding of difficult concepts. The eLearning project was designed to support students and academics in problem-based learning. It aimed to provide resources for academics to enable problem- based teaching and learning. The project had five scenarios representing different areas in nursing, each of these being underpinned by information to support students and linked to websites.

University D uses an open learning approach aimed at allowing students to learn in their own time by reading course material, working on course activities, and completing assignments. The courses use a variety of different media including; printed course materials, audio cassettes, video cassettes, and cd-rom/software. The teaching and learning priorities are to embed eLearning and the use of information and communications technology (ICT) at the centre of the student experience through the widespread use of the VLE. The University decided that all course provision would migrate to a new VLE, but individual course teams determine the extent to which they use the new VLE. The Course Chair was responsible for the adherence to institutional policies and procedures and advised the course team about electronic innovations that were to be introduced in the future.

The Case E is a pre-1992 University with about 19,000 students almost equally divided between undergraduate and postgraduate programmes. The eLearning strategy is driven by the Professor for eLearning. The eLearning project was built on the work carried out by the University investigating assessment practices based on e-tivities and their impact on the learner experience that aimed to: embed good practice in re-design for e-learning, build capacity within the institution, enhance the learner experience, make tutors' jobs more 
effective and rewarding, and stimulate institutional change. The eLearning project is underpinned by an interventionist approach through a two-day workshop in which disciplinespecific course teams, in collaboration with subject librarians and learning technologists. The Professor for eLearning was of the view that developing capabilities for staff to adopt on learning technologies was more important than imposing institutional strategy. This involves the choice of easy to use technologies and investment in personal, course and departmental learning, thus, developing capabilities for the longer term and keeping 'ownership' with the academic departments. University E implemented a project driven by the e-learning research unit. The research unit had designed a specific training and support method, which was used to help teams develop e-learning courses.

\section{Research design}

A qualitative and exploratory case study method was deemed the most appropriate way to enhance understanding of e-learning approaches because it allows researchers to delve deeply into phenomena and to do so within real-life contexts (Perry, 1998). According to Yin (1981), a case study is an appropriate research approach when human activity is embedded in the real world and can only be studied or understood in its context, and where the boundary between context and organisation cannot be easily drawn. The current study is suited to case study research because one of its primary aims is to build an understanding of the adoption and diffusion of e-learning through rich analysis of interaction between agency and structure. The research question for this study is: how do agency and structure interact to contribute to the adoption of e-learning in five universities in the United Kingdom? This type of contextspecific research question readily lends itself to case study research.

Semi-structured interviews were used as the main data collection method in this study. Case study researchers have acknowledged that interviews provide an important source of information because they allow in-depth and detailed qualitative data to be collected by aiding the researcher in becoming physically and psychologically closer to the phenomena (Tellis, 1997). The first phase of data collection consisted of interviews with three e-learning professors (cases A, C, and E) and two senior members of e-learning project teams (cases B and D). A further 52 interviews were then conducted with heads of academic departments, academic staff, e-learning and information technology (IT) staff that had responsibilities across the whole of the institutions, and academic teaching staff who were involved in developing e-learning courses. All interviews were conducted face to face and lasted between 80 and 90 minutes. All interviews were recorded and transcribed verbatim by 
the researcher in person; therefore, the researcher's understanding of the data is apt (Rogers, 1995).

\section{Results}

Giddens' structuration framework has been used to analyse interaction between agency and structure. The three modalities; interpretative scheme, facility and norm form the basis for cross-analysis between the data collected.

The interpretative scheme focuses on two themes; signification and communication. Signification is concerned with how the individual makes sense of eLearning. The structuration in the interpretative scheme examines the individuals' involvement with the eLearning strategy development and the communication of the strategy. There are two components to this theme, the first being the interaction between the individual and the eLearning strategy and second the influence of the strategy on the individual's motivation to adopt, or reject, eLearning.

The findings show that, in all five case institutions, e-learning strategies were developed, discussed, and approved by senior managers. Whilst senior managers responsible for e-learning claimed that there was widespread collaboration and that feedback was sought during the development of the strategy, this view was not shared by the academic staff. In all five cases investigated, there was evidence that senior manager was developing e-learning strategies with only notional contributions from other stakeholders. Academic staff commented, for example:

I am only an academic and would not expect to be consulted ... its [development of elearning strategy] is blue sky thinking and mine is to do the job. (Academic Staff Member, University A)

We were made aware of it [e-learning strategy] during the teaching and learning away day ... my recollection was that it would be something that it was a fait accompli and you really had to buy in ... from my perspective it was not really a discussion. (Head of Academic Department, University B)

"it [eLearning strategy] was emailed to me at the same time as everyone else when it was done. There was no consultation with the respondent during the development phase of the strategy". (Academic Staff Member, University C)

The data suggest that academic staff perceive themselves to be excluded from important decisions relating to the diffusion of e-learning within their institutions. Rogers (2003, p. 29) 
used the term "authority innovation" to refer to a situation wherein an organisation's leaders make decisions without significant or meaningful input from the potential adopters. Findings from the five case studies showed that authority innovation decisions were made by relatively few individuals in higher management levels, and academic staff had little or no influence in these decisions. If academic staff are not involved in high-level decision making, they may perceive themselves to be marginalised in important decisions relating to their roles within the institution (de Freitas \& Oliver, 2005).

Mass media channels (e.g., e-mail and institutional intranet) were prominent methods of communicating e-learning strategy in all five institutions. Whilst such communication channels may reach large numbers of staff members, evidence from the interviews revealed that most academic staff were unaware or dismissive of their institutions' e-learning strategies:

I was emailed a document [e-learning strategy] a few months ago ... I didn't have any input to this at all. If I did see it then it's because I am on the circulation list ...I am far too busy to look through it in detail. (Academic Staff Member, University A) Have I seen the e-learning strategy? Should I have? I think I should know ... I am not saying it is the school's fault, it may be my fault. (Academic Staff Member, University B)

It's one of those documents for validation ... Do I use the document regularly now? Probably not. It doesn't affect too much the day-to-day delivery of an award. (Academic Staff Member, University D)

In three of the cases investigated, the senior management's communication style could be described as "launch and disappear" (a term used by an academic staff member), whereby a member of senior management team presents the strategy as an invited guest at a faculty meeting. Such methods had little or no influence on engagement of academic staff in elearning initiatives.

Academic staff identified number of different pragmatic factors driving their decisions to adopt e-learning.

“... using technology mainly for extending programmes that have failed to recruit on the traditional face to face programmes, using technology they offered programmes to a diverse international market”. (Academic Staff Member, University E)

The respondent claimed the initial motivation for the institution was to increase the number 
of student numbers through eLearning courses, however, recently, according to the respondent, current motivator for eLearning is to driven by the student expectations

“... one [driver] is the students, student experience of e-learning tends to lead them to want more so they express themselves to their lecturers so that means lecturers who previously might have been reluctant, might have said well what is the benefit to us, are now responding to student pressure to do something". (Academic Staff Member, University C)

Giddens (1984) proposed that one of the forces underlying individual motivation is psychological anxiety. Similarly, Rogers (2003, p. 176) suggested that "preventive innovation" occurs when an individual adopts a new idea in order to avoid the possible occurrence of some unwanted event in the future. In the cases examined for this study, these unwanted events included closure of a course, having to retrain in a different academic discipline, possible redundancy, and pressure to take additional tasks due to reduced teaching workload, all of which contributed to decisions to adopt e-learning.

Analysis of the interviews showed that academics rationalised decisions not to change by invoking a lack of resources, conflict with pedagogical approaches, and academic freedom and autonomy. In the words of two academic staff members:

I have developed a good set of learning materials... The students are happy, they perform very well in the assessment - so why change? (Academic Staff Member, University E)

Many people were very scared of this not knowingness, of the uncertainty... Most [academics] are used to a stable environment... Some simply rejected developing elearning courses. (Course Leader, University D).

Giddens (1984) used the term "ontological security" to describe a state wherein individuals maintain their routine patterns of behaviour to continue to experience positive and stable emotions and to avoid the chaos and anxiety that change can bring.

\section{Facility: Domination and Power}

The modality of facility, in terms of the adoption of eLearning, examines the motivational support and guidance provided by managers and other colleagues. Management commitment and support is an important factor that can hinder or enable the adoption of e-learning (Benson \& Palaskas, 2006; Marshall, 2004). Academic staff interviewed for this study 
reported very little contact with senior managers. In cases A and D, academic staff stated that support from local managers was significant in their decisions to develop e-learning courses. The interpersonal relationships, access to resources, and acknowledgment of innovative practices were perceived as representations of middle managers support and engaged academic staff.

"I think departmentally my Programme Area Manager is very good and has set time aside in departmental meetings, away days to discuss eLearning" (Academic Staff Member, University A)

"She [Departmental Manager] is one of the best networkers I have seen in my life, not in the IT sense in the interpersonal sense. Her making her connections throughout the university really helped to develop the infrastructure that we needed to develop... helped to advocate for the kind of things that we wanted to do make sure we had the resources available to do it and so I think it would have failed miserably" (Academic Staff Member, University D)

\section{Modality Norm: legitimation and sanctions}

Giddens' third modality in the Duality of Structure framework refers to Norms as the moral codes that provide both understandings and sanctions for human interactions. Sanctions, refers to the constraining aspects of power, ranging from the application of force to the expression of disapproval. The modality or norm is concerned not with the actual sanctions but with how individuals choose to respond to them.

Although there were no direct sanctions for non adoption of e-learning in any of the five case institutions, in two of the institutions (A and B), academics were expected to adhere to top-down directives. In case A, senior management team had produced an audit checklist that was used to audit all e-learning courses, and in case B, the head of teaching and learning had directed that all e-learning courses must incorporate eSubmission facility. In both cases, as illustrated by the academic staff members' comments, the top-down directives were rejected.

I am responsible for what I am delivering and I don't feel that I need to be checked up on ... I felt that the people who were monitoring what I was delivering did not have any knowledge about my subject so they had to change the system (Academic Staff Member, University A)

I think there is a health and safety issue in regards to online marking ... so I informed the head of the e-learning that I was withdrawing from this project (Academic Staff 
member, University A).

Giddens' (1984) suggested that individuals are rarely in positions where they are wholly incapable of resisting such directives and that no "matter how oppressive and comprehensive they may be, [managers] demand some kind of acquiescence from those subject to them" (p. 175). In case $\mathrm{E}$, the senior manager (Professor for eLearning) recognised top-down directives would not be very productive.

"There is an attempt to put this college structure together. It won't make the slightest bit of difference. Every unit does their own thing and peoples' commitment is to their discipline and it's not to the University"

The potential new adopters favourably regarded the respected colleagues who had successfully introduced e-learning, because they perceived those colleagues to be successful under conditions that were similar to their own (e.g., decreasing student numbers on traditional campus-based courses, access and availability of resources and support, balancing different priorities). Academic staff were comfortable interacting with colleagues with whom they shared characteristics, and, by interacting with successful adopters, they derived a sense of optimism that had significant bearing on their decisions to develop e-learning courses. A number of academic staff in case A acknowledged that the adoption of e-learning by close colleagues was an influential factor in their own behaviour. Additionally, they perceived as a useful resource shared ideas from groups who had successfully adopted e-learning. As one staff member noted,

"They have a much better pedigree — they have been doing it a much longer. So using their experience has helped a lot this year to gain new ideas... It is better having a cross-pollination of ideas, the people who have extensive experience should provide one-to-one mentoring."

Similarly, another academic staff member from the same university commented, "Whenever I had a concern or uncertainty about how to do something, I would often contact them... They already had a course up and running, so I had access to their resources in terms of style and the approach to pedagogy they had used... We pretty much adopted what they had that was very successful."

These findings support Rogers' (2003) view that there is likely to be an effective "transfer of 
ideas between individuals who belong to the same groups, sharing similar interests and common meanings, beliefs, and mutual understanding" (p. 19). He further argued that individuals enjoy the comfort of interacting with others who are similar and that they are more likely to adopt an innovation if similar individuals have adopted it previously. Peers can be powerful opinion leaders who can persuade their colleagues to see the benefits of, and to utilise, an innovation (Rogers, 2003).

\section{Summary and Discussion on levers for change}

In all of the five cases investigated there was evidence that eLearning strategies were being developed by the senior management with notional contributions from the potential adopters of eLearning. This form of organisational centralisation (decision-making is concentrated with only a small group of people) was negatively associated with the adoption and diffusion of eLearning. The findings suggest that the decisions to adopt eLearning were, in the main, not influenced by the institutional eLearning strategy but by contextual, intrinsic, and pragmatic factors. The evidence from the data collection suggested that a diverse range of reasons existed why individuals chose to adopt eLearning, including: decreasing numbers of students on traditional campus-based courses, curiosity, the desire to develop innovative courses, and the need to meet the changing student expectations. Institutional leaders need to manage and draw on these diverse motivators and avoid imposing institutional constraints through standardised frameworks that assume a single solution for all eventualities.

The consensus in the e-learning literature is that senior managers who develop elearning strategies need to consider stakeholders at all levels to ensure their strategies do not have a damaging effect on the adoption of e-learning (Backhouse, 2013; Ng'ambi \& Bozalek, 2013). Thus senior managers may need to consider a collaborative, participatory approach to shaping the direction of e-learning strategy (Bates \& Sangra, 2011).

The analysis of the interviews suggests that an individual is more likely to adopt an innovation if other individuals in his or her personal network has adopted previously. This is more likely when adopters influence their peers to adopt by providing them with positive evaluation of the eLearning. An individual's network links are important determinant of his or her adoption of eLearning, thus, managers need help form social networks drawing together potential adopters with near peers who have successfully implemented eLearning.

We found that peers are powerful opinion leaders who can persuade their colleagues to see the benefits of, and to utilise, innovations (Rogers, 1995). The findings from the case projects confirmed that positive support of peers with similar interests, beliefs, and mutual 
understandings promoted decisions and levels of e-learning adoption. Such peer groups provide informal support for communicating information, building and preserving new knowledge, and providing a way to express professional identity (Sharpe, Benfield \& Francis, 2006). Our research reinforced the notion that faculty members do not learn in isolation, but rather socially, through a community of peers (Salmon \& Angood, 2013), and diffusion is a social process of change whereby innovations are created and shared in both a spontaneous and planned way (Rogers, 2003).

Multiple communication channels need to be used in diffusion of eLearning. Whilst, mass media channels can reach a large number of individuals and change weakly held attitudes, however, interpersonal communication approaches need to be deployed to overcome strongly held attitudes. A two-way exchange of information and interpersonal networks can help overcome the social-psychological barriers to adoption of eLearning. The role of interpersonal channels is especially important in persuading an individual to adopt a new idea. Findings from this study suggest that both types of communication methods should be adopted. Mass media channels are important at the knowledge stage and interpersonal channels are relatively more important at the persuasion stage.

There is a need to encourage senior managers to facilitate e-learning by endorsing bottom-up engagement. For example, some faculty have their own requirements and targets for engaging with university e-learning strategy. Such mechanisms can facilitate debate and exploration of emerging technologies as ways to achieve faculty and university goals whilst allowing staff to articulate and voice their beliefs about teaching and learning with technology (Sharpe, Benfield \& Francis, 2006, p. 141). This form of integrative approach can provide the foundations for a balance of top-down and bottom-up requirements. Acceptance of e-learning innovations by members of subject disciplines (Schneckenberg, 2010) can determine whether and how e-learning is likely to be adopted. We found in our case studies that senior managers need to recognised that faculties and departments have their own desires, abilities, histories, and preferred artefacts (Salmon, 2005, p. 206), and such cultural differences have implications for the diffusion of e-learning (Gibbs \& Gosper, 2006).

\section{Conclusion}

The aim of this study was to identify and examine the inhibitors and enablers that influence the convergence of top-down and bottom-up approaches, and propose a set of change management levers to structures that enable the effective development, adoption, and diffusion of e-learning. Reliance solely on mass media tools to communicate eLearning 
strategy, not recognising individual (intrinsic, pragmatic) drivers for adoption of elearning, centralised support structures, and top-down directives were amongst the inhibitors of eLearning adoption. Examination of the interviews revealed that potential adopters of eLearning were more likely to adopt eLearning for pragmatic (preventative innovation) and intrinsic (inquisitive, professional development) reasons. Furthermore, personal communication, support from local management and personal contacts encouraged the adoption of eLearning.

Using Gidden's Theory of Structuration, the study provided some important indicators of key elements in understanding the relationships between top-down and bottomup approaches. The analysis of the five cases shows that there remain significant limitations in the approaches the universities used, which did not fully engage with the agency- and structure-related dimensions of e-learning adoption that ought to be "perceived as a social process that requires interaction between human actors and institutional features" (Giddens, 1984, p. 25). The findings from this study have implications for universities managing the adoption and diffusion of e-learning. In particular, by implementing processes that bridge agency and structure, universities may be able to enhance the adoption and diffusion of elearning. Giddens' theory of structuration provides a useful framework for understanding the dynamics of organisational change as they pertain to the adoption and diffusion e-learning innovations. Developing and managing sustainable structures that provide effective interaction between agency and structure is the key role of university leaders who hope to enhance the adoption and diffusion of e-learning.

\section{References}

Backhouse, J. (2013). What makes lecturers in higher education use emerging technologies in their teaching? Knowledge Management \& E-Learning, 5(3), 345-358.

Bates, A., \& Sangrà, A. (2011). Managing technology in higher education: strategies for transforming teaching and learning. San Francisco, CA: Jossey-Bass.

Benson, R. and Palaskas, T., 2006. Introducing a new learning management system: An Institutional Case Study. Australasian Journal of Education Technology, 22(4) pp. 548-567.

Bhowmick, S. (2015) Structurational explication of technology adoption: A throwback to Giddens. In ICT in Development. London, United Kingdom: Palgrave Macmillan. 
Birch, D. and Burnett, B. (2009) Bringing academics on board: Encouraging Institution-wide Diffusion of eLearning Environments Australasian Journal of Educational Technology, 25(1), pp.117-134

Brooks, L., Atkinson, C., \& Wainwright, D. (2008) Adapting structuration theory to understand the role of reflexivity: problematization, clinical audit and information systems. International Journal of Information Management. 28(6), 453-460.

de Freitas, S., \& Oliver, M. (2005). Does E-learning policy drive change in higher education? A case study relating models of organisational change to e-learning implementation. Journal of Higher Education Policy and Management, 27(1), 81-96. doi:10.1080/13600800500046255

Drlika, M., \& Skalkaa, J. (2011). Virtual faculty development using top-down implementation strategy and adapted EES model procedia. Social and Behavioral Science, 28, 616-621. doi:10.1016/j.sbspro.2011.11.117

Gibbs, D., \& Gosper, M. (2006). The upside-down-world of e-learning. Journal of Learning Design, 1(2), 46-54.

Giddens, A. (1984). The constitution of society: Outline of the theory of structuration. Berkeley, CA: University of California Press.

Hardaker, G., Dockery, R., \& Sabki, A., (2010). Cognitive learning styles and digital equity: searching for the middle way. International Journal of Inclusive Education, 14(8), 777-794. doi:10.1080/13603110802680786

Jones, M., \& Karsten, H. (2008). Giddens's structuration theory and information systems research. MIS Quarterly, 32(1), 127-157.

Lisewski, B. (2004). Implementing a learning technology strategy: top-down strategy meets bottom-up culture. Association of Learning Technology - Journal, 12(2), 175-188. doi:10.1080/0968776042000216228

Marshall, S. (2004). Leading and managing the development of E-Learning environments: An issue of comfort or discomfort? Institute Of Higher Education Research and Development 2004 Proceedings Ascilite. Retrieved 4 January, 2013, from www.ascilite.org.au/conferences/perth04/.../marshall-keynote.html

Marshall, S. (2010). Change, technology and higher education: Are universities capable of organisational change? Journal of Asynchronous Learning Networks, 18(3), 22-34.

Ng'ambi, D., \& Bozalek, B. (2013). Leveraging informal leadership in higher education institutions: A case of diffusion of emerging technologies in a southern context. British Journal of Educational Technology, 44(6), 940-950. doi:10.1111/bjet.12108 
Nicol, D., \& Draper, S. (2007, 11-14 June). Understanding the prospects for transformation. Institutional Transformation: The JISC Innovating e-Learning 2007 online conference.

Oblinger, D. (2012). IT as a game changer. In D. G. Oblinger (Ed.), Game changers: Education and information technologies (pp. 37-52). Washington, DC: Educause.

Orlikowski, W. and Robey, D. (1991). IT and the structuring of organizations. Information Systems Research, 2(2), 143-169. doi:10.1287/isre.2.2.143.

Osika, E. (2006) The concentric support model: A model for the planning and evaluation of distance learning programs. Online Journal of Distance Learning Administration, 9(3). [Accessed 11 Aug 2008]. Available at: http://www.westga.edu/ distance/ojdla/fall93/osika93.pdf

Perry, C. (1998). Processes of a case study methodology for postgraduate research in marketing. European Journal of Marketing, 32(9/10), 785- 802.

Rogers, E. (1995). Diffusion of innovations. New York, NY: Free Press.

Rogers, E. (2003). Diffusion of innovations (5th ed.). New York, NY: Free Press.

Rose, J. (1998, June). Evaluating the contribution of structuration theory to the information systems discipline. In 6th European Conference on Information Systems, Granada.

Rose, J. and Hackney, R. (2003) Towards a Structurational Theory of Information Systems: a substantive case analysis, Hawaii International Conference on Systems Science, Hawaii.

Salmon, G. (2005. Flying not flapping: a strategic framework for e-learning and pedagogical innovation in higher education institutions ALT-J. Research in Learning Technology, 13(3), 201-218. doi:10.1080/09687760500376439

Salmon, G., \& Angood, R. (2013). Sleeping with the enemy. British Journal of Educational Technology, 44(6), 916-925. doi:10.1111/bjet.12097

Schneckenberg, D. (2010). Overcoming barriers for e-learning in universities-portfolio models for eCompetence development of faculty. British Journal of Educational Technology, 41(6), 979-991. doi:10.1111/j.1467-8535.2009.01046.x

Sharpe, R. Benfield, G., \& Francis, R. (2006). Implementing a university e-learning strategy: levers for change within academic schools. ALT-J, Research in Learning Technology, 14(2), 135-151. doi:10.1080/09687760600668503

Singh, G., \& Hardaker, G. (2014). Barriers and enablers to adoption and diffusion of elearning: a systematic review of the literature - A need for an integrative approach. Education + Training, 56(2), 105-122. 
Stiles, M., \& Yorke, J. (2006). Technology supported learning - Tensions between innovation, and control and organisational and professional cultures. Journal of Organizational Transformation and Social Change, 3(3), 251-267. doi:10.1386/jots.3.3.251_1

Tellis, W. (1997). Introduction to case study. The Qualitative Report, 3(2) [Serial online]. Accessed 28 July, 2013, from http://www.nova.edu/ssss/QR/QR3-2/tellis1.html Yin, R. (1981). The case study crisis: Some answers. Administrative Science Quarterly. 26(1), 58-65. doi:10.2307/2392599 